\title{
Global Food Insecurity and African, Caribbean, and Black (ACB) Populations During the COVID-19 Pandemic: a Rapid Review
}

\author{
Charles Dabone $^{1,2} \cdot$ Ikenna Mbagwu ${ }^{1,2}\left(\right.$ D $\cdot$ Mwali Muray ${ }^{1,2} \cdot$ Lovelyn Ubangha $^{2} \cdot$ Bagnini Kohoun $^{2,3} \cdot$ Egbe Etowa $^{2,4}$. \\ Hilary Nare ${ }^{1,2} \cdot$ Getachew Kiros $^{1,2} \cdot$ Josephine Etowa ${ }^{1,2}$
}

Received: 20 October 2020 / Revised: 17 January 2021 / Accepted: 18 January 2021 / Published online: 8 February 2021

(C) W. Montague Cobb-NMA Health Institute 2021

\begin{abstract}
Background The global food insecurity reinforces the ongoing impact of COVID-19 on human health and mortality. Although literature remained sparse, reports indicated that food insecurity is disproportionately high among African, Caribbean, and Black (ACB) population since the outset of COVID-19. Hence, we assessed the food insecurity conditions of ACB populations globally during the COVID-19 pandemic.

Methods Comprehensive searches in CINAHL, Medline (Ovid), PubMed (Medline), Food Science and Technology Abstracts, SCOPUS, EMBASE, AMED, CAB Abstracts, Cochrane Library (OVID), and PsycINFO were carried out. Title/abstract and full-text screening, quality appraisal (modified JBI QARI), and data extraction were carried out by double reviewers.

Results The initial search yielded 354 articles. After removal of duplicates and irrelevant articles, a full-text review and critical appraisal, 9 papers were included in the study. After data extraction and synthesis, six major themes emerged from the analysis: increased food insecurity, adverse health outcomes of food insecurity, exacerbation of existing disparities, systemic inequities and adverse policies, racism, and sociocultural response and solutions.

Conclusion/implications The study showed that COVID-19 had exacerbated food insecurity and other health disparities within racialized populations including ACB people, due to systemic anti-Black racism; inadequate representation in decision-making; and issues of cultural appropriateness and competency of health services. While sociocultural response by ACB people through the expansion of their social capital is imperative, specific policies easing access to food, medicine, and shelter for racialized communities will ensure equity while reducing global food insecurity and health crises during the COVID-19 pandemic.
\end{abstract}

Keywords Food insecurity $\cdot$ COVID-19 $\cdot$ African, Caribbean, and Black (ACB) population $\cdot$ Global $\cdot$ Health

\section{Introduction}

The world is no stranger to challenges and tragedies. Despite the varying magnitude in devastation triggered by local and global problems, the SARS-CoV-2 disease (SARS-CoV-2/

Charles Dabone

cdabone@uottawa.ca

Ikenna Mbagwu

imbagwu@uottawa.ca

1 Faculty of Health Sciences, University of Ottawa, Ottawa, Canada

2 Canadians of African Descent Health Organization (CADHO), Ottawa, Canada

3 Immigration, Refugees and Citizenship Canada, Ottawa, Canada

4 Department of Sociology, Anthropology \& Criminology, Faculty of Arts, Humanities \& Social Sciences, University of Windsor, Windsor, Canada
COVID-19) has caused tremendous tribulations across the globe. Since it was first reported in December 2019 in Wuhan City, China, COVID-19 has spread to virtually all corners of the world causing untold adverse outcomes such as increased mortality and exacerbation of food insecurity within already marginalized populations [1,2].

Food insecurity - which refers to the unsustainable access to adequate supplies of good quality foods to meet the biological, developmental, and functional needs of humans for a healthy and normal life - has presented new challenges in a rapidly evolving world population [3, 4]. Globally, there are more than 820 million hungry people while about 2 billion people experience moderate to severe food insecurity [4]. In developed countries, the issue hits severely marginalized subgroups of the population including racial minorities. For instance, in the USA, food insecurity affects Black people $(21.2 \%)$ more than any other racial groups, at a rate higher than the national average of $11.1 \%$ [5, 6]. In Canada, the 
prevalence of food insecurity is approximately 3.5 times more in Black households compared to White households at a national level [7].

With the negative impact of the ongoing COVID-19 pandemic, it is estimated that the number of people at risk of starvation globally will double-from 135 million to 265 million-by the end of 2020 [1, 3]. In the USA, counties which have a large population of Native Americans and African-Americans - such as Navajo County in Arizona and Orleans Parish in Louisiana - are projected to have some of the highest food insecurity rates as the ongoing pandemic rages on [8]. Likewise in Canada, it is also expected that the food insecurity situation will double from the existing 4.4 million, further impacting racialized populations as a result of factors such as unemployment, reduced income, and food-price spikes [9]. Many countries — such as those in the Horn of Africa, Central America and Caribbean, Western Africa, and parts of Asia - that rely on essential agricultural seasons may be impacted by reduced agricultural workforce, or reduced access to agricultural inputs, due to a combination of the lockdown measures and supply chain disruptions. Consequently, this could lead to spikes in food-price in these low-income countries, and other long-term repercussions [1].

More specifically among marginalized populations including African, Caribbean, and Black (ACB) populations, food insecurity has become disproportionately high since the COVID-19 pandemic started, as there have been reports of lack of access to healthy food, food unaffordability, and food unavailability [8, 10-12]. The recent COVID-19 Impact Survey which collected data on American adults in May 2020 indicated that more than half of Black respondents with children reported that they were food insecure, and over $40 \%$ of Hispanic respondents with children reported food insecurity [13]. All the more, the pandemic has had indirect impacts on the food insecurity experience of Black people. For instance, about $39 \%$ of jobs held by Black American workers have become vulnerable due to reduced pay at work, short-term furloughs, or outright layoffs [12]. Such economic circumstances have, in turn, led to the difficulty in purchasing nutritious food [14]. Similarly, since ACB people rely on essential public services such as public transportation to be able to access food at grocery stores, ongoing containment measures such as lockdown and restrictions on movement have worsened the already precarious food insecurity situation [12, 15]. Even though some of the factors that exacerbated the food insecurity among ACB population are apparent, it is worthy to note that this current food insecurity experience could be traced to years of structural disparities, longstanding health and economic inequities that systematically place ACB and other marginalized populations at socioeconomic disadvantages $[5,10]$.

A few studies have successfully shown that food insecurity is disproportionately high among marginalized populations such as ACB people [5-7]. However, there remains a paucity of reviews documenting the global food insecurity experience of the ACB population during the ongoing COVID-19 pandemic. Hence, the aim of this review was to assess the current state of the literature regarding food insecurity, food accessibility, and food availability during the SARS-CoV-2 outbreak among ACB populations around the world. This knowledge would enable policy makers, global leaders, and other stakeholders to develop and implement specific policies and programs that will reduce the burden of food insecurity among marginalized communities worldwide, including ACB populations.

\section{Methods}

\section{Literature Search}

The search strategy was done in efforts to answer the research question: "What is the experience of food insecurity among ACB people during the COVID-19 pandemic?" More particularly, we sought to find out "How the COVID-19 pandemic has affected the food insecurity condition among ACB populations."

Ten electronic databases were consulted to find scholarly publications and gray literature pertinent to the research question. CINAHL, Medline (Ovid), PubMed (Medline), Food Science and Technology Abstracts, SCOPUS, EMBASE, AMED: Allied and Complementary Medicine Database, CAB Abstracts, Cochrane Library (OVID), and PsycINFO were perused for articles published between December 2019 and June 2020, available in either English or French. Keywords, and their truncated forms, used for the search were those referring to COVID-19, ACB, race and marginalization, as well as food insecurity (ex: [ COVID or COVID-19 or Coronavirus or "Corona virus" ] AND [ Black* or African* or Afro* or Carib* or Race* or racial* or racis* or minorit* or marginali* ] AND [ food* or deficienc* or nutri* or hunger or hungry ]). The inclusion and exclusion criteria are listed in Appendix I.

Qualitative, quantitative, and methodological articles were retained for the review, as well as media reports and press releases, given the novelty of the topic and the need to reach audiences of various levels of education and literacy. Searching and the use of gray literature for rapid reviews has become increasingly important during the COVID-19 pandemic [16]. Also, the National Collaborating Center for Methods and Tools [17] suggests conducting "an exhaustive search for all available evidence - both quantitative and qualitative, published and grey literature - that address the issue." The references and publications were managed using the EndNote X8 software package, following which they were 
added to the online Covidence software to facilitate the collaborative review process.

\section{Eligibility Criteria}

Population The population of interest was the African, Caribbean, and Black (ACB) population across the globe with diverse sociodemographic characteristics such as sex, age (children, adolescents, adults, elderly), geographic regions (rural, urban), employment, income, education, and socioeconomic status.

Exposure Exposure to the Severe Acute Respiratory Syndrome Coronavirus 2 (SARS-CoV-2) virus that is responsible for the COVID-19 pandemic was selected in lieu of an intervention.

Comparison The comparison to the chosen ACB population was in reference to various population groups that did not identify as ACB people such as White (Caucasians), Latino/ Hispanic, Indigenous people, and Asians.

Outcomes Outcomes that were assessed were the impacts and effects of the COVID-19 pandemic on food insecurity and other socioeconomic realities ACB people faced, includingbut not limited to - access to food, availability of food, and use of food, as well as health status, behaviors, and perceptions regarding the stability of availability, access, and use of food.

Time Period Articles published between December 2019 and June 2020 were retained for this review.

\section{Quality Appraisal}

Ensuring the quality of papers and data to be collected was a critical component of the rapid review. Hence, the quality of included studies was assessed by two independent reviewers using a modified Joanna Briggs Institute Qualitative Assessment and Review Instrument (modified JBI QARI) Critical Appraisal Instrument (Appendix II). This modified instrument consists of a total of thirteen questions and was adapted by combining three questions from the Critical Appraisal Skills Programme (CASP) Qualitative Appraisal Checklist [18] with ten questions from the JBI QARI [19]. The thirteen questions on the modified JBI QARI tool were uploaded to Covidence, and a risk of bias (ROB) assessment was carried out for each paper by the two independent reviewers. For each question on the tool, the reviewers were to choose between High, Unclear, or Low ROB. A High ROB was assigned 0 point, Unclear ROB was issued 0.5 point, and Low ROB obtained 1 point. A maximum score of 13 was assigned to the modified JBI QARI tool and a grading system was then created to assess the quality of each paper: High = 10-13; Moderate $=6-9$; Low $=0-5$. Hence, a total score was then computed for each paper. Any disagreements that arose between the two reviewers were resolved by a third reviewer.

\section{Data Extraction}

Qualitative data were extracted by two independent reviewers from the included papers using the standardized data extraction tool from JBI-QARI [20]. The data extracted included specific details about the populations, setting, culture, geographical location, study methods, and the phenomena of interest relevant to the review question and specific objectives. Additionally, findings - and their illustrations - were also extracted and assigned a level of credibility.

\section{Data Synthesis}

Following the extraction and tabulation of data, the table derived was used to inform a narrative synthesis. Initially, all authors read the table of findings repeatedly and independently so as to identify prevalent concepts in the outcome categories when observed through a health-equity lens. These prevalent concepts and themes were provided to the research team. Subsequently, all the identified concepts were then grouped and clustered by two of the authors to synthesize major themes and sub-themes. Thereafter, all authors reviewed and discussed the themes and sub-themes, which would be used as a basis for evidence-based practice and informed this written rapid review. Meta-analysis (or meta-aggregation) was not performed as this was a rapid review and the design, methods, and settings of included studies were heterogenous.

\section{Results}

\section{Study Selection}

The initial search yielded 354 articles. Removal of duplicates allowed for 69 articles to be deleted. With 285 articles remaining, 222 articles were deemed irrelevant following the title and abstract screening. This allowed for 63 articles to undergo a full-text review. Twenty-six articles were then excluded, as they were not sufficiently relevant-notably, 9 articles failed to mention ACB people, another 9 articles did not mention food security, and 8 articles were excluded for other reasons (such as lack of availability). After this process, 37 articles were included for a full appraisal. At this time, the literature search was updated, ensuring that the most current data was reflected in this publication. Still, by June 2020, 37 articles were reviewed at the quality appraisal phase (Fig. 1).

The 37 papers were critically appraised for the quality of their study methods. The summary of the score and quality of 
354 studies imported for screening

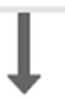

285 studies screened

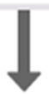

63 full-text studies assessed for eligibility

37 studies included
69 duplicates removed

222 studies irrelevant

26 studies excluded

$\checkmark$

9 No mention of $A C B$ people

9 No mention of food security

4 Wrong study design

2 Not available in written media

2 Wrong setting

$\mathbf{0}$ studies ongoing

0 studies awaiting classification

Fig. 1 Study flow diagram

the 37 papers is listed in Appendix III. The decision as to whether or not to include a study was made based on meeting the pre-determined score for either moderate or high quality. Only nine papers were of moderate or high quality (Appendix IV) and, thus, were included for the data extraction process.

\section{Characteristics of Included Studies}

The nine (9) studies included in this rapid review are classified in two categories: four (4) were online news reports [21-24] while five (5) were peer reviewed articles [25-29]. The studies and reports presented here were all published in 2020 including four (4) related to the USA [21, 22, 26, 28], three (3) related to Africa [23, 24, 27], one (1) related to developing countries in general [29], and a last one related to a global perspective [25]. From all these studies, only one has collected original data involving 1478 adults [26]. The rest of the studies were comments [27], theoretical perspectives [25, 28, 29], or just a press release report [21, 23, 24]. While some of the studies focused specifically on ACB population [23, 24, 27], the majority focused on minorities and marginalized communities [21, 22, 25, 26, 28, 29].

\section{Synthesis of Findings (Outcomes of Included Studies)}

Relevant data from each included study are listed in Table 1. However, overall, the analysis of the data highlighted six major themes: increased food insecurity, adverse health outcomes of food insecurity, exacerbation of existing disparities, systemic inequities and adverse policies, racism, and sociocultural response and solutions (Table 2). As food insecurity may be experienced differently due to the difference in geographical location, we presented the themes according to developed countries (USA) and developing countries (Kenya, South Africa, etc.).

\section{Themes that Emerged from a Developed Country (USA)}

\section{Increased Food Insecurity}

Food insecurity increased during the COVID-19 pandemic through three aspects. Firstly, the food demand is greater than what is available. At the time of the COVID-19 pandemic, many people relied on community organizations that provided food relief services. As a consequence, food demand has 


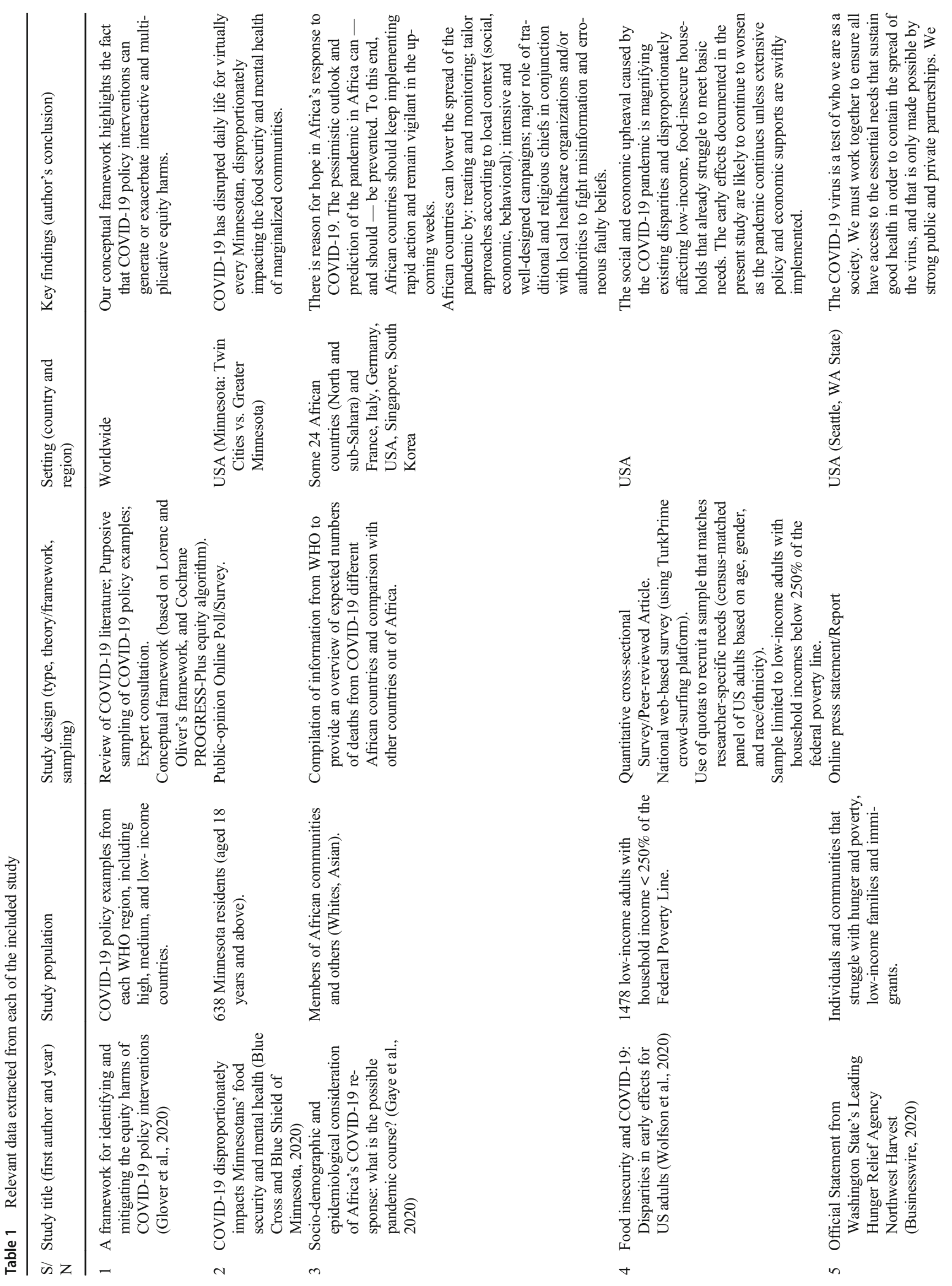




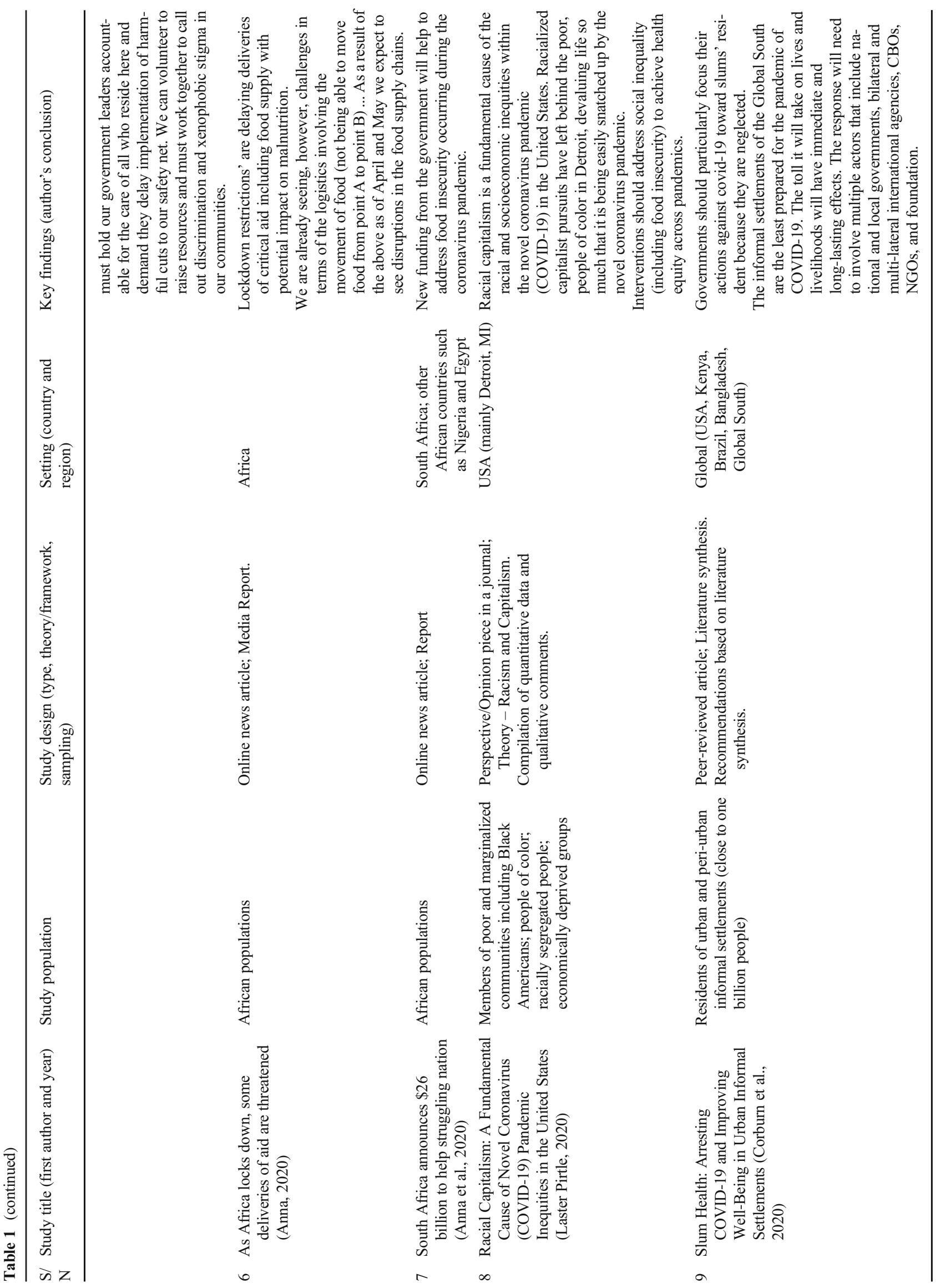




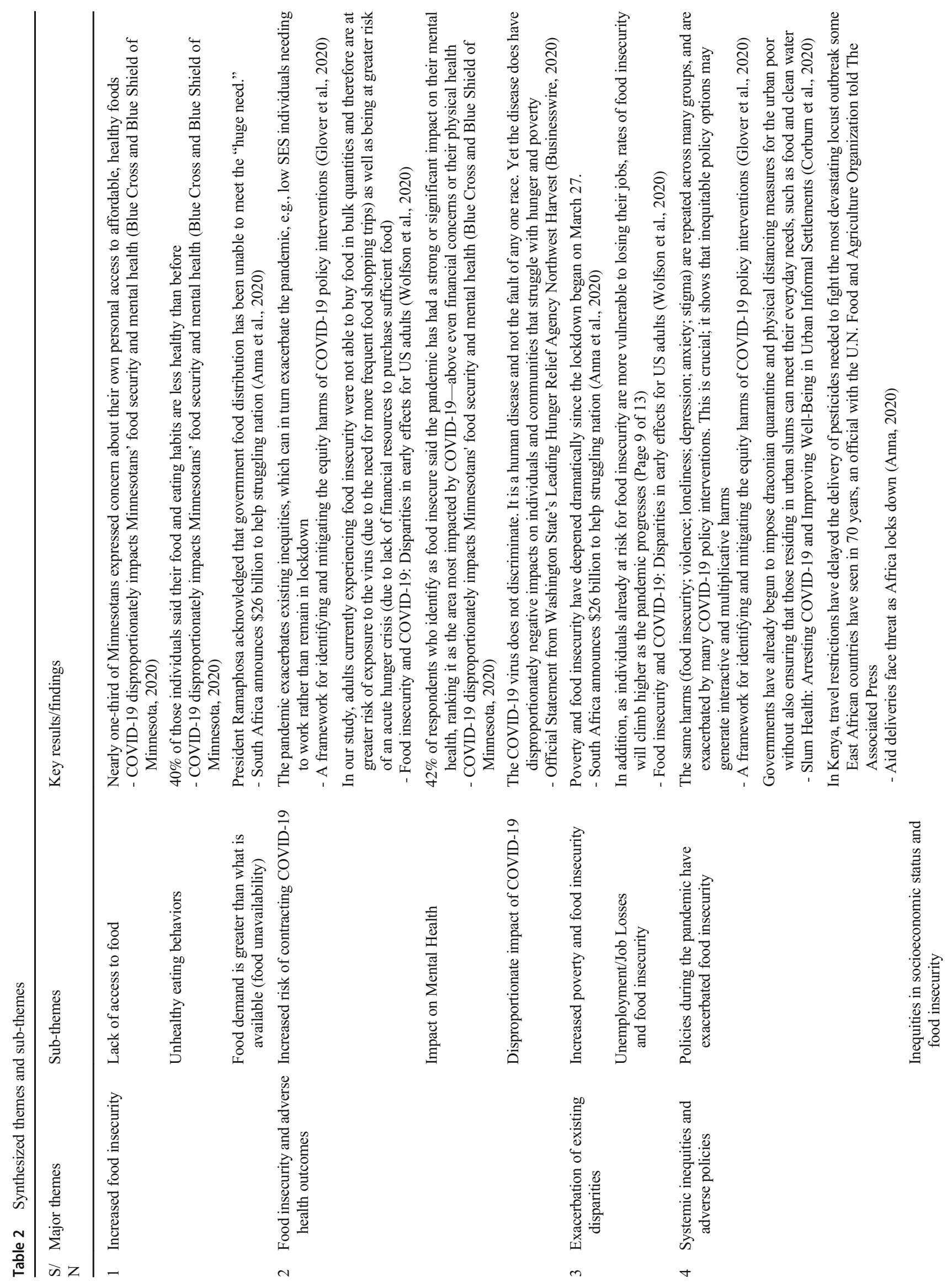




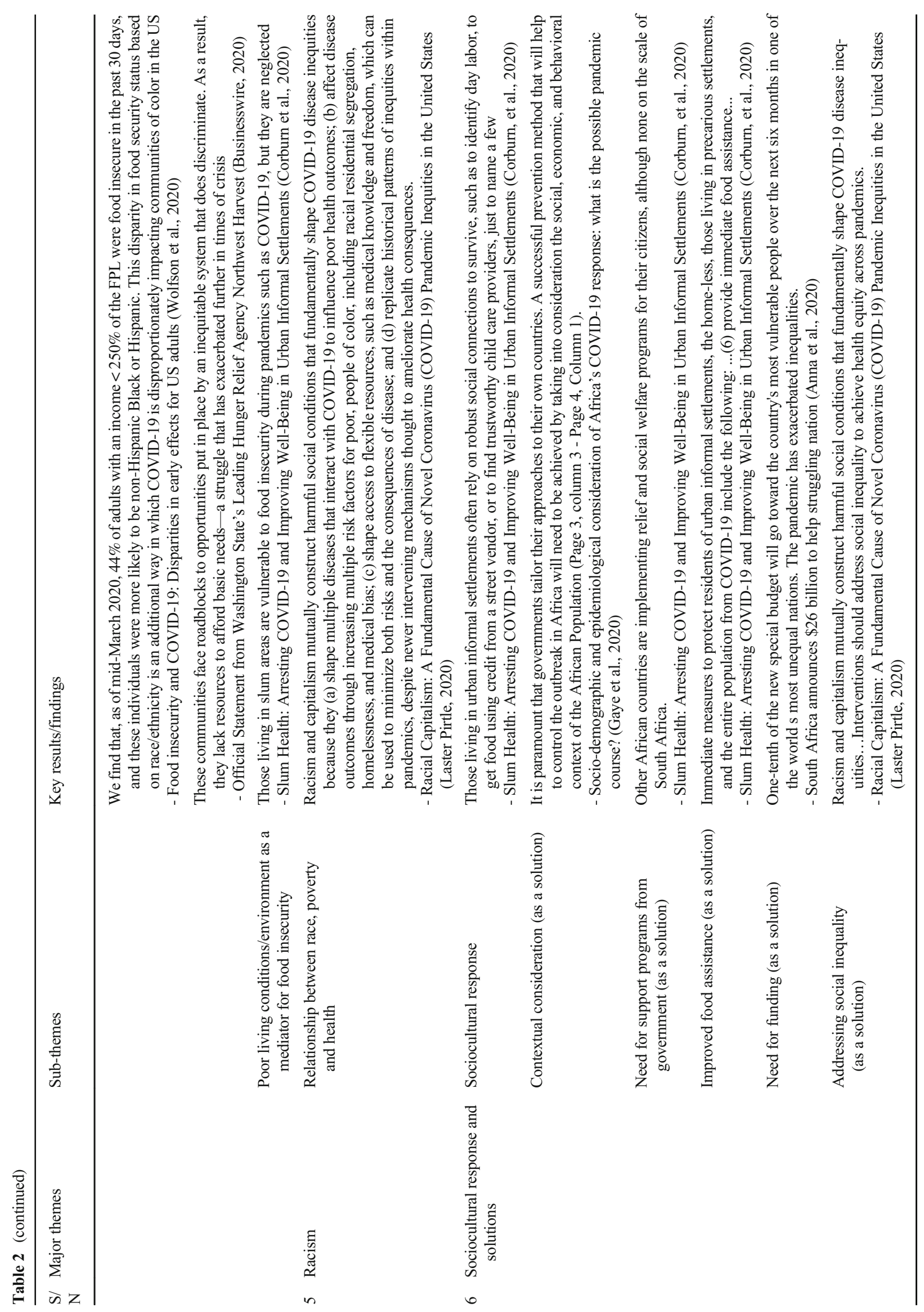


increased making the demand greater than what is available. Secondly, this unavailability induced a lack of access to food. This was mentioned by an official of the Blue Cross and Blue Shield of Minnesota [21] who revealed that:

We all feel the toll of COVID-19, but it is particularly alarming to see how the pandemic is exacerbating existing health inequities and impacting so many Minnesotans' access to healthy and affordable foods.

Thirdly, the lack of food availability and accessibility led people to adopt unhealthy eating behaviors. According to the Blue Cross and Blue Shield, $40 \%$ of Minnesotans said their food and eating habits are less healthy than before [21].

\section{Food Insecurity and Adverse Health Outcomes}

The reviews of the studies included here reveal that during the pandemic, ACB communities experienced some adverse health outcomes as a result of food insecurity. Firstly, a disproportionate impact of COVID-19 was seen among ACBs compared to other racial groups in spite of the fact that the disease does not discriminate among humans:

The COVID-19 virus does not discriminate. It is a human disease and not the fault of any one race. Yet, the disease does have disproportionately negative impacts on individuals and communities that struggle with hunger and poverty. [22]

It was also noted that the issue of food insecurity has increased the risk of contracting COVID-19. Indeed, in their study, Wolfson and Leung (2020) [26] reported that:

Adults currently experiencing food insecurity were not able to buy food in bulk quantities and therefore are at greater risk of exposure to the virus (due to the need for more frequent food shopping trips) as well as being at greater risk of an acute hunger crisis (due to lack of financial resources to purchase sufficient food).

Finally, one study showing that food insecurity affected more ACB people also highlighted that food insecurity had an impact on their Mental Health [21]:

Forty-two percent of respondents who identify as food insecure said the pandemic has had a strong or significant impact on their mental health, ranking it as the area most impacted by COVID-19 - above even financial concerns or their physical health.
Racism

Relationship Between Race, Poverty, and Health One study [28] also shows that the food insecurity situation experienced by the ACB population is deeply linked to racism. Racism contributes to poverty and affects minorities through its duality with capitalism, as they mutually construct harmful social conditions that fundamentally shape COVID-19 disease inequities. The authors further stated that:

Indeed, historical research on smallpox reveals that if access to flexible basic resources, like food, medicine, shelter, and treatment, excluded any subset of the population, the disease will continue to spread and continue to kill. [28]

\section{Themes that Emerged from Developing Countries (Africa, Kenya, South Africa, etc.)}

\section{Exacerbation of Existing Disparities}

Increased Poverty and Food Insecurity Poverty and food insecurity have deepened dramatically since the lockdown began. Indeed, they became top priorities for many African countries, including South Africa according to the President of South Africa, Cyril Ramaphosa [23]:

The top priorities are combating the virus and relieving "hunger and social distress" as millions of South Africans struggle to survive under lockdown.

Unemployment/Job Losses and Food Insecurity In addition, as individuals already at risk for food insecurity are more vulnerable to losing their jobs, rates of food insecurity will climb higher as the pandemic progresses. This is mentioned in this excerpt below:

It's extremely important that food systems continue to function ... but also be able to move across borders. Lockdowns and other restrictions for the coronavirus may affect us very, very much on a continent where millions of people who must go out daily to make a living are made to stay at home. [24]

\section{Sociocultural Response and Solutions}

The majority of studies included in this review highlighted the sociocultural response and solutions to consider when dealing with the situation within ACB and other marginalized 
communities. These are the following (and corresponding quotes supporting the key strategies): social context, contextual consideration, support programs from government, improved food assistance, need for funding, and addressing social inequality.

Social context and response:

Those living in urban informal settlements often rely on robust social connections to survive, such as to identify day labor, to get food using credit from a street vendor, or to find trustworthy child care providers, just to name a few. [29]

Contextual consideration:

It is paramount that governments tailor their approaches to their own countries. A successful prevention method that will help to control the outbreak in Africa will need to be achieved by taking into consideration the social, economic, and behavioural context of the African Population. [27]

Need for support programs from government:

Nigeria's government has announced it will expand its social welfare register from 2.6 million households to 3.6 million, in addition to food distribution...Cape Verde has offered cash transfers and food assistance...Egypt has reduced taxes for industries and postponed taxes on agricultural land. [23]

Other African countries are implementing relief and social welfare programs for their citizens. [29]

Improved food assistance:

Governments should support existing community-based organizations (CBOs), faith-based groups, and others that may already be providing food support to the poor and ensure they can deliver cooked meals to all those in the informal settlements and living on the streets. Efforts should be made to ensure adequate nutritional content, including protein, of all delivered food. [29]

Need for funding:

One-tenth of the new special budget will go toward the country's most vulnerable people over the next six months in one of the world s most unequal nations. The pandemic has exacerbated inequalities. [23]
Addressing social inequality:

Indeed, historical research on smallpox reveals that if access to flexible basic resources, like food, medicine, shelter, and treatment, excluded any subset of the population, the disease will continue to spread and continue to kill. [28]

\section{Themes that Emerged from Both Developed and Developing Countries}

\section{Systemic Inequities and Adverse Policies}

Policies During the Pandemic Have Exacerbated Food Insecurity The results of this review demonstrate that inequitable policies implemented systematically may generate interactive and multiplicative harms. As reported by Corburn et al. [29], governments have already begun to impose draconian quarantine and physical distancing measures for the urban poor without also ensuring that those residing in urban slums can meet their everyday needs, such as obtaining food and accessing clean water. These lockdown policies have also exacerbated food insecurity as reported by Gaye et al. (2020) [27] and Corburn et al. (2020) [29] respectively:

Given the low socioeconomic status in most of African cities, mass quarantines may mean people will starve, as many of them already struggle to find food on a daily basis, much as has been reported in deprived neighborhood in the USA. [27]

Schools often provide essential nutrition and meals for children living in slums, and closing those institutions may deny children access to their only consistent meals. [29]

Certain harms such as food insecurity, violence, loneliness, and stigma are disproportionately repeated across marginalized groups, and are exacerbated by many COVID-19 policy interventions [25]. For example in Kenya, an official with the U.N. Food and Agriculture Organization told The Associated Press that "travel restrictions have delayed the delivery of pesticides needed to fight the most devastating locust outbreak some East African countries have seen in 70 years." [24]. This situation can contribute to the alteration of the food system that is already weak in many African countries. As underlined in the report released by $\mathrm{ABC}$ News:

With the rainy season starting now, farmers start planting and ranch-land begins regenerating. But if these 
voracious insects are landing on these young crops, then these farmers will be facing a $100 \%$ loss. [24]

Inequities in Socioeconomic Status and Food Insecurity Existing socioeconomic inequities within communities, specifically against minorities including ACBs, have an impact on food insecurity. In their study, Wolfson and Leung [24] found that:

....as of mid-March 2020, 44\% of adults with an income $<250 \%$ of the Federal Poverty Line (FPL) were food insecure in the past 30 days, and these individuals were more likely to be non-Hispanic Black or Hispanic. [26]

Also, according to the authors:

This disparity in food security status based on race/ ethnicity is an additional way in which COVID-19 is disproportionately impacting communities of color in the US. [26]

Above these, the socioeconomic status of marginalized communities is linked to the food insecurity situation:

Individuals with low or very low food security were more likely to be non-Hispanic Black or Hispanic, to have children in the home, and have less than a college education. Individuals with very low food insecurity were also more likely to rent their homes, not have health insurance or have Medicaid, and were more likely to be receiving Supplemental Nutrition Assistance Program (SNAP) benefits. [26]

In fact, more results further highlighted the socioeconomic constraints and the link to food insecurity, as stated below [22]:

These communities face roadblocks to opportunities put in place by an inequitable system that does discriminate. As a result, they lack resources to afford basic needs - a struggle that's exacerbated further in times of crisis. [22]

...the lack of affordable childcare or reduction of hours worked means missed or reduced paychecks. Stockpiling emergency supplies of food is a daunting expense - especially when you can barely afford to eat on a day-by-day basis. [22]
Poor Living Conditions/Environment as a Mediator for Food Insecurity The study also reveals that people living in slums were vulnerable to food insecurity during the COVID-19 pandemic [29]. The excerpts below illustrate the situation:

Malnutrition and food insecurity is endemic in many urban slums throughout the world. Urban slum dwellers rely on day wages to purchase food, and street food vending is often a significant source of calories and nutrition. [29]

Residents in deprived neighbourhoods have less access to green spaces and healthy, affordable foods. [28]

\section{Discussion}

\section{Food Insecurity and Its Adverse Effects}

Food insecurity is a complex condition that encompasses four fundamental dimensions namely food availability, food accessibility, food utilization, and food stability [30]. During the current study, we found that food insecurity increased through its availability, accessibility, and utilization dimensions within ACB communities due to the COVID-19 pandemic. Hence, the rising food demand has affected food availability. According to Nicola et al. (2020) [31], this increase is a consequence of the panic-buying and stockpiling of food products in the early days of the pandemic, when people feared that existing food will run out.

In addition to existing challenges, food availability has been impacted by the disruption of the food supply chains, which is a consequence of the closure of borders on a global scale [32]. As a result, the supply of food to markets has become more difficult [33] with a direct impact on availability of food at the household level. Additionally, accessibility of food became difficult during the pandemic, both physically and economically. Economically, increased demand is causing increased food prices especially for healthier options such as vegetables [34].

The precarious conditions in which many disadvantaged communities are living have also made physical accessibility more difficult. Unable to buy large amount of food for storage, the poorest have to continue working despite the public health lockdown measures, in order to be able to feed themselves and fulfill basic needs $[11,12]$. The consequence is that in addition to not being able to eat a healthy diet, they must go out to purchase food despite the risk of being infected by the virus 
due to increased exposure to others. Thus, food insecurity itself appears as a risk factor for contracting the disease for the poorest. On the other hand, it has been reported that a poor diet poses a risk of weakening the immune system, thereby compromising the body's ability to fight diseases [35, 36].

As Black communities in many developed countries struggle with so many chronic diseases, there was a concern that they would have to pay a heavy price in face of COVID-19. In this regard, the early released statistics from the USA clearly showed how a huge number of ACB people died from COVID-19 or complications of the disease [37]. The pandemic has contributed to exacerbating the already precarious health conditions of Black populations [38]. Furthermore, the issue of mental health is the one that we noted as a stark consequence of food insecurity. This is understandable since the fear and stress induced by unhealthy eating behaviors and food scarcity are well documented [39]. This can even be more serious when children are present in the household, as many of them lost access to school meals due to the COVID19 pandemic [40, 41].

\section{Exacerbation of Disparities-Increased Poverty, Unemployment, and Food Insecurity}

The social and economic impacts of the COVID-19 pandemic have exposed the precarious position of the underserved populations of which the ACB community makes up a significant part. It is projected that COVID-19 will push 71 million people into extreme poverty in 2020: with Africa and India being the most affected regions [42]. Poverty and minority statusespecially being Black - have since been linked to food insecurity; thus, the COVID-19 pandemic has further worsened an already dire situation [43, 44].

Minority populations make up a significant proportion of workers considered essential such as retail grocery workers, public transit employees, health-care workers, and custodial staff, many of whom are low-income earners [45]. As such, many survive paycheck to paycheck and do not have the financial ability to stockpile food items. Several complicated food management and purchase strategies which low-income households adapted to maintain food security have been described, and these involved long-term budgeting, buying products on sale, buying unbranded products, and buying the cheapest items from multiple stores. In addition, the increased job insecurity and lack of cheaper food items on the grocery shelves make such survival strategies difficult at best and impossible at worst, further worsening the inability to purchase food and increasing food insecurity [10, 46].

Moreover, in a bid to slow down the spread of the virus, several governmental policies were put in place worldwide, including temporary closure of many businesses so as to adhere to social distancing measures. Using Canada as a case study, from February to April 2020, about 5.5 million
Canadian workers were affected by the COVID-19 economic shutdown. This included a drop in employment of 3.0 million jobs and an increase in COVID-19-related absences from work of 2.5 million [47]. As an attempt to reduce the impact of the economic fallout, various governments from predominantly high-income countries implemented relief measures which were expected to reduce food insecurity. These involved stimulus checks to employees who experienced income-loss due to the pandemic, as well as various protections to businesses, enabling them to retain some of their staff [48]. With the exclusion of most European countries, most stimulus checks are however significantly lower than the usual salary of the individuals, and many households have seen a reduction in their income for a significant time period [49].

With a proportionate increase in use of food banks globally, Canada is not spared. For instance, the CEO of Canada Food Banks compared the current increase of food bank use (20\%) to the Great Depression, when the use of food banks increased 28\% across the country [50]. As such, the policy measures implemented during the COVID-19 crisis have been insufficient to prevent increases in poverty and food insecurity.

\section{Systemic Inequities and Adverse Policies}

In Western countries - and particularly in Canada with a universal healthcare system — one might wonder why the experiences of the ACB population during the pandemic would be different from that of any other Canadian. This is exactly the type of uninformed belief which this study sought to address by sharing the specific experience of hardships lived by ACB populations. Social determinants are known to account for the disproportionate health risks and differential health outcomes experienced in the ACB communities during the COVID-19 pandemic. These include systemic anti-Black racism; poor representation in healthcare leadership, research and decision-making; lack of culturally appropriate services; and lack of culturally competent health [51]. Systemic racism is often very subtle. It affects people not only at an interpersonal level but also through the broader structures of society, most notably in the systems of justice, media, public policing, immigration, and employment, as well as through hate activity and government policies [52]. As a result of these inequities, people of African descent and those in the western nations including Canada are often more prone to pre-existing health conditions including diabetes and high blood pressure. Also, they represent some of the most vulnerable populations in terms of their susceptibility to health risks and particularly to COVID-19 [53].

The unprecedented pandemic has highlighted how preexisting socioeconomic inequities have negatively impacted the ACB community's ability to fight back against the SARSCoV-2. Since the World Health Organization (WHO) 
declared COVID-19 as a pandemic on March 11, 2020, countries worldwide reacted through various measures intended to contain the spread of the virus. Governments have put in place policy interventions such as lockdown measures of various stringencies, public spaces or workplace closures and restrictions on internal and external movements focusing on social distancing [25].

The policy interventions were aimed at shielding populations against the virus to prevent overwhelming countries' healthcare systems and to quickly get control of the pandemic. However, many of these measures produced adverse effects and created unique hardships for struggling families and vulnerable populations $[25,27]$. For example, lockdown measures requiring citizens to stay at home may be seen as simple and logical measures to achieve social distancing and prevent the spread of the disease. However, the direct implications of these seemingly simple and benign measures show that families with low income may lack basic needs such as food [22].

Stay at home measures for the ACB communities and other marginalized groups happened to be an impossible task particularly in low- and middle-income countries where people need to go out on a daily basis to secure food for their families. For those populations, one day inside the house is equal one day of starvation and COVID-19 is the least of the existential problems they are facing. Many African countries have closed their borders to mitigate the impact of the COVID-19 pandemic. Even though these policy measures seem well-intended, the immediate results of their implementation are that many countries experienced shortages of food, health items, and other vital necessities and supplies [24].

This study shows that the ACB community has been severely impacted by the COVID-19 pandemic due to preexisting inequalities that were exacerbated by the disease. Moreover, COVID-19 policy interventions were mostly topdown decisions that did not always take into account the perspectives of vulnerable populations [29]. In Canada, for example, concerns have been voiced about the absence of appropriate race-based data collection [54]. Without such data, policy makers may not fully understand how the pandemic is affecting different communities in order to design appropriate policy interventions. The different lived experiences of $\mathrm{ACB}$ people included in this study revealed that food insecurity is not an isolated issue, but just one of the multiple intersecting barriers and hardships that the community is facing in these unprecedented times.

\section{Racism}

The relationship between race, poverty, and health is one that cannot be ignored. Longstanding societal inequities have predisposed ACB populations to numerous disadvantages. Groups that were already marginalized and facing disproportional struggles saw these challenges heightened in the wake and aftermath of the COVID-19 pandemic $[55,56]$. The Government of Canada [57] acknowledges race and racism as determinants of health, recognizing that they are factors that have historically affected the lives of Canadians of African Descent (CAD), and that can continue to yield health inequalities. The concerning situation regarding food security is not novel, as especially vulnerable groups such as immigrants and refugees, and individuals living in rural and remote regions struggle to obtain access to resources that are readily available to other communities. When adding challenges such as socioeconomic disparity, whereby wealthier individuals tend to have better health outcomes than those with lower incomes or those living in poverty, many ACB people are faced with challenges in which their race causes them to face greater disadvantages than their White counterparts [58, 59].

The intersection of multiple detrimental factors-from oppressively racist policies to societal xenophobia and discrimination - contributes to the marginalization of ACB people, affecting the previously healthy and those with existing health challenges, alike [22, 28, 29]. Heightened risk factors include the over-representation of racialized essential workers, decreased access to resources for pre-existing health issues, and concomitant reduction in access to vital resources, from health services to healthy and affordable food [10, 28]. Policies meant to protect the public are found to cause greater harms when they do not consider the social contexts of racialized people, from those living in racially segregated and disadvantaged neighborhoods, to advisories enforcing distancing and isolation, not considering the contexts and lived experiences of those residing in slums, multi-family households, those detained or in correctional settings, or those experiencing homelessness [28, 29]. As racialized individuals tend to be over-represented in these precarious situations, in order to mitigate existing and potential disparities, considerations of particular needs of these groups must be at the forefront of health planning, not in hindsight or as an afterthought.

The power inequities that are heightened when considering racism and vulnerabilities of ACB people cannot be ignored, as they have historically affected Blacks and will continue to cause stigmatization, marginalization, and poor health outcomes within this population group. "The racial time bomb" continues to tick and jeopardize the lives of ACB people [28, 60]. Until race and racism are considered in identifying the needs and mitigating the harms of the most racially disadvantaged communities, the fight against COVID-19 will remain a long shot.

\section{Sociocultural Response and Solutions}

This rapid review identified some ways in which marginalized communities have responded to the food insecurity exacerbated by the pandemic, such as relying on strong social connections to survive, identifying day labor to engage in so as to 
make more money to be able to afford food, and getting food using credit from street vendors [29]. Similarly, household response to food insecurity has been documented in literature, as households have been found to utilize various mechanisms such as crop diversification, contract farming, household savings, and agricultural intensification to cope and adapt [61].

However, it is important to note that any strategy that will successfully control the COVID-19 outbreak and its effect among ACB population will need to consider the social, economic, and behavioral contexts of people of African descent [27]. Hence, this review found some strategies that are being used by some countries to mitigate the burden of food insecurity among ACB people during the COVID-19 pandemic. This includes immediate food assistance to their citizens, provision of special budgets for the most vulnerable people, expansion of food distribution process, and cash transfers [23, 29]. Such strategies have also been utilized in the past during disease outbreaks to alleviate the impact on food insecurity. For instance, during the 1918 influenza pandemic, organizations such as the American Red Cross and Tuberculosis Society assisted affected families with salaries, food for convalescents, and up to 100 quarts of milk per day, and volunteers also prepared meals for patients at community kitchens opened by the U.S. Food Administration [62]. Conclusively, other possible ways in which countries can build the competence of their food systems during pandemics have been suggested, including elimination of food wastage, utilizing byproducts of food processing in the context of emergencies, and identifying the most critical threats to the food system so as to tackle them proactively [63].

Ultimately, addressing social inequality by providing access to basic resources such as food, medicine, and shelter for racialized communities has been identified as a possible solution to help achieve health equity during pandemics such as the COVID-19 crisis [28].

\section{Strengths and Limitations}

To the best of our knowledge, this rapid review is the first in its kind, exploring the issue of global food insecurity within the ACB population amidst the COVID-19 pandemic.

However, there are several limitations to the review methods employed here. Firstly, there were few peerreviewed papers related to this study. Similarly, most of the papers retrieved from the search strategy were moderate- to low-quality gray literature, and the design, methods, and settings of the included studies were heterogenous, making metaaggression difficult to execute. Finally, our study included only studies published in French and English. Thus, we may have missed studies published in other languages. However, the included studies were selected to thoughtfully tailor the rapid review according to current evidence, the urgent nature of the task, and the need to provide timely results.

\section{Implications and Conclusions}

During these challenging times, the measures discussed above are welcome, and useful in the short-term to mitigate the effects of food insecurity in light of the COVID-19 pandemic. However, food insecurity is still an ongoing challenge globally which many ACB people have experienced long before the pandemic came into play. With COVID-19 disproportionately affecting the ACB population, there is a double burden of both disease and food insecurity. As such, policies, programs, and long-term solutions, which are specifically tailored to the unique needs of this demographic, are necessary to proactively tackle food insecurity within the ACB community. Since the future is unknown and pandemics are unpredictable, results of this rapid review will empower individuals, communities, and nations to be better prepared peradventure another outbreak hits our shores.

Supplementary Information The online version contains supplementary material available at https://doi.org/10.1007/s40615-021-00973-1.

Availability of data and material Not applicable Code availability Not applicable

Author contribution All the authors contributed to the conceptualization of the study, literature search, quality appraisal, data extraction, data analysis, and manuscript development. All authors read and approved the final manuscript.

\section{Declarations}

Conflict of interest The authors declare no competing interests.

\section{References}

1. World Food Programme. COVID-19 - Potential Impact on the world's poorest people. Rome, Italy; 2020. https://www.wfp.org/ publications/covid-19-potential-impact-worlds-poorest-people. Accessed 17 Aug 2020.

2. World Health Organization. Coronavirus disease 2019 (COVID19) Situation Report-85. Geneva, WHO, 2020. https://www.who. int/docs/default-source/coronaviruse/situation-reports/20200415sitrep-86-covid-19.pdf?sfvrsn=c615ea20_4. Accessed 16 Aug 2020.

3. Food Security Information Network. 2020 Global report on food crises: joint analysis for better decisions. Rome, Italy and Washington, DC: Food and Agriculture Organization (FAO); World Food Programme (WFP); and International Food Policy Research Institute (IFPRI). 2020. https://www.fsinplatform.org/ global-report-food-crises-2020. Accessed 17 Aug 2020.

4. Food and Agriculture Organization of the United Nations. The state of food security and nutrition in the world 2019: safeguarding 
against economic slowdowns and downturns, Rome, FAO. 2019. https://doi.org/10.4060/CA5162EN. Accessed 17 Aug 2020.

5. Coleman-Jensen A, Rabbitt MP, Gregory CA, Singh A. Household food security in the United States in 2018. 2020. http://www.ers. usda.gov/publications/pub-details/?pubid=94848. Accessed 17 Aug 2020.

6. Hernandez DC, Reesor LM, Murillo R. Food insecurity and adult overweight/obesity: gender and race/ethnic disparities. Appetite. 2017;117:373-8. https://doi.org/10.1016/j.appet.2017.07.010.

7. Tarasuk V, Mitchell A. Household food insecurity in Canada, 2017-18. Toronto: research to identify policy options to reduce food insecurity (PROOF). 2020. https://proof.utoronto.ca/ resources/proof-annual-reports/household-food-insecurity-incanada-2017-2018/. Accessed 24 May 2020.

8. Feeding America. The impact of the coronavirus on local food insecurity: analysis of how food insecurity may increase in 2020 due to COVID-19 for the overall population and children by state, county, and congressional district. 2020. https://www. feedingamerica.org/sites/default/files/2020-05/Brief_Local\% 20Impact_5.19.2020.pdf. Accessed 18 Aug 2020.

9. Food Secure Canada. Growing resilience and equity: a food policy action plan in the context of Covid-19. 2020. https:// foodsecurecanada.org/sites/foodsecurecanada.org/files/2020-05_gre_en_12_49.pdf. Accessed 15 Aug 2020.

10. Ebbs S 'Cascading failures of the state': COVID-19 impacts on health, food security amplifying George Floyd protests. $A B C$ News. June 05, 2020. https://abcnews.go.com/Politics/cascadingfailures-state-covid-19-impacts-health-food/story?id=71086399

11. Feeding America. The impact of the coronavirus on food insecurity. 2020. https://www.feedingamerica.org/sites/default/files/2020-04/ Brief Impact $\% 20$ of $\% 20$ Covid $\% 20$ on $\% 20$ Food $\% 20$ Insecurity $\%$ 204.22\%20\%28002\%29.pdf. Accessed 18 Aug 2020.

12. Florant A, Noel N, Stewart III S, Wright J. COVID-19: investing in black lives and livelihood. McKinsey \& Company. April 14, 2020. https://www.mckinsey.com/industries/public-sector/our-insights/ covid-19-investing-in-black-lives-and-livelihoods\#

13. Schanzenbach DW, Pitts A. Estimates of food insecurity during the COVID-19 crisis: results from the COVID Impact Survey, Week 2 (May 4-10, 2020). Institute for Policy Research Rapid Research Report. 2020. https://www.ipr.northwestern.edu/documents/ reports/food-insecurity-covid_week2_report-18-may-2020.pdf. Accessed 18 Aug 2020.

14. Maani N, Galea S. The true costs of the COVID-19 pandemic. Scientific American. April 13, 2020. https://blogs. scientificamerican.com/observations/the-true-costs-of-the-covid19-pandemic/. Accessed 17 Aug 2020.

15. Stephens EC, Martin G, van Wijk M, Timsina J, Snow V. Editorial: Impacts of COVID-19 on agricultural and food systems worldwide and on progress to the sustainable development goals. Agric Syst. 2020;183:102873. https://doi.org/10.1016/j.agsy.2020.102873.

16. Tricco AC, Garritty CM, Boulos L, Lockwood C, Wilson M, McGowan J, et al. Rapid review methods more challenging during COVID-19: commentary with a focus on 8 knowledge synthesis steps. J Clin Epidemiol. 2020;126:177-83. https://doi.org/10.1016/ j.jclinepi.2020.06.029.

17. Dobbins M Rapid Review Guidebook: steps for conducting a rapid review. National Collaborating Center for Methods and Tools, 2017. https://www.nccmt.ca/uploads/media/media/0001/01/ a816af720e4d587e13da6bb307df8c907a5dff9a.pdf. Accessed 11 Aug, 2020.

18. Critical Appraisal Skills Programme. CASP Qualitative Checklist. 2018. https://casp-uk.net/wp-content/uploads/2018/03/CASPQualitative-Checklist-2018_fillable_form.pdf. Accessed 10 June 2020.

19. Lockwood C, Munn Z, Porritt K. Qualitative research synthesis: methodological guidance for systematic reviewers utilizing meta- aggregation. Int J Evid Based Health. 2015;13(3):179-87. https:// doi.org/10.1097/XEB.0000000000000062.

20. Joanna Briggs Institute. Appendix 2.3: JBI Qualitative data extraction tool. 2020. https://wiki.jbi.global/display/MANUAL/ Appendix $+2.3 \% 3 \mathrm{~A}+\mathrm{JBI}+$ Qualitative+data+extraction+tool. Accessed 10 Jun 2020.

21. Blue Cross and Blue Shielf of Minnesota. COVID-19 disproportionately impacts Minnesotans' food security and mental health. $P R$ Newswire. May 07, 2020. https://www.prnewswire.com/newsreleases/covid-19-disproportionately-impacts-minnesotans-foodsecurity-and-mental-health-301054696.html. Accessed 16 Aug 2020.

22. Businesswire. Official Statement from Washington State's Leading Hunger Relief Agency Northwest Harvest. Businesswire. March 13, 2020. https://www.businesswire.com/news/home/ 20200313005542/en/. Accessed 16 Aug 2020.

23. Anna C, Magome M. South Africa announces $\$ 26$ billion to help struggling nation. $A B C$ News. April 21, 2020. https://abcnews.go. com/International/wireStory/south-africa-announces-26-billionstruggling-nation-70271896. Accessed 09 Aug 2020.

24. Anna $\mathrm{C}$ As Africa locks down, some deliveries of aid are threatened. $A B C$ News. April 03, 2020. https://abcnews.go.com/ International/wireStory/africa-locks-deliveries-aid-threatened69957567\#: :text=JOHANNESBURG\%20\%2D\%2D\%20More\% 20than $\% 20$ half,delaying $\% 20$ deliveries $\% 20$ of $\% 20$ critical $\% 20$ aid

25. Glover RE, van Schalkwyk MCI, Akl EA, Kristjannson E, Lotfi T, Petkovic J, et al. A framework for identifying and mitigating the equity harms of COVID-19 policy interventions. J Clin Epidemiol. 2020;128:35-48. https://doi.org/10.1016/j.jclinepi.2020.06.004.

26. Wolfson JA, Leung CW. Food insecurity and COVID-19: disparities in early effects for US adults. Nutrients. 2020;12(6):1648. https://doi.org/10.3390/nu12061648.

27. Gaye B, Khoury S, Cene CW, Kingue S, N'Guetta R, Lassale C, et al. Socio-demographic and epidemiological consideration of Africa's COVID-19 response: what is the possible pandemic course? Nat Med. 2020;26(7):996-9. https://doi.org/10.1038/ s41591-020-0960-y.

28. Laster Pirtle WN. Racial capitalism: a fundamental cause of novel coronavirus (COVID-19) pandemic inequities in the United States. Health Educ Behav. 2020;47(4):504-8. https://doi.org/10.1177/ 1090198120922942.

29. Corburn J, Vlahov D, Mberu B, Riley L, Caiaffa WT, Rashid SF, et al. Slum health: arresting COVID-19 and improving well-being in urban informal settlements. J Urban Health. 2020;97(3):348-57. https://doi.org/10.1007/s11524-020-00438-6.

30. Ashby S, Kleve S, McKechnie R, Palermo C. Measurement of the dimensions of food insecurity in developed countries: a systematic literature review. Public Health Nutr. 2016;19(16):2887-96. https://doi.org/10.1017/S1368980016001166.

31. Nicola M, Alsafi Z, Sohrabi C, Kerwan A, al-Jabir A, Iosifidis C, et al. The socio-economic implications of the coronavirus pandemic (COVID-19): A review. Int J Surg. 2020;78:185-93. https://doi. org/10.1016/j.ijsu.2020.04.018.

32. Cappelli A, Cini E. Will the COVID-19 pandemic make us reconsider the relevance of short food supply chains and local productions? Trends Food Sci Technol. 2020;99:566-7. https://doi.org/10. 1016/j.tifs.2020.03.041.

33. Nature Plants. Food in a time of COVID-19. Nat Plants. 2020;6: 429. https://doi.org/10.1038/s41477-020-0682-7.

34. Akter S. The impact of COVID-19 related 'stay-at-home' restrictions on food prices in Europe?: Findings from a preliminary analysis. Food Secur. 2020;12:1-7. https://doi.org/10.1007/s12571020-01082-3.

35. Butler MJ, Barrientos RM. The impact of nutrition on COVID-19 susceptibility and long-term consequences. Brain Behav Immun. 2020;87:53-4. https://doi.org/10.1016/j.bbi.2020.04.040. 
36. Handu D, Moloney L, Rozga M, Cheng F. Malnutrition care during the COVID-19 pandemic: considerations for registered dietitian nutritionists evidence analysis center. J Acad Nutr Diet. 2020. https://doi.org/10.1016/j.jand.2020.05.012.

37. Anyane-Yeboa A, Sato T, Sakuraba A. Racial disparities in COVID-19 deaths reveal harsh truths about structural inequality in America. J Intern Med. 2020;288(4):479-80. https://doi.org/10. 1111/joim. 13117.

38. Lassale C, Gaye B, Hamer M, Gale CR, Batty GD. Ethnic disparities in hospitalisation for COVID-19 in England: The role of socioeconomic factors, mental health, and inflammatory and proinflammatory factors in a community-based cohort study. Brain Behav Immun. 2020;88:44-9. https://doi.org/10.1016/j.bbi.2020. 05.074 .

39. Di Renzo L, Gualtieri P, Cinelli G, et al. Psychological aspects and eating habits during COVID-19 home confinement: results of EHLC-COVID-19 Italian Online Survey. Nutrients. 2020;12(7): 2152. https://doi.org/10.3390/nu12072152.

40. Dunn CG, Kenney E, Fleischhacker SE, Bleich SN. Feeding lowincome children during the Covid-19 pandemic. $N$ Engl J Med. 2020;382(18):e40. https://doi.org/10.1056/NEJMp2005638.

41. Van Lancker W, Parolin Z. COVID-19, school closures, and child poverty: a social crisis in the making. Lancet Public Health. 2020;5(5):e243-4. https://doi.org/10.1016/S2468-2667(20)300840 .

42. Lakner C, Mahler DG, Negre M, Prydz EB. How much does reducing inequality matter for global poverty? (English). Global Poverty Monitoring Technical Note; 13 Washington, D.C. : World Bank Group. 2020. http://documents.worldbank.org/curated/en/ 765601591733806023/How-Much-Does-Reducing-InequalityMatter-for-Global-Poverty. Accessed 18 Aug 2020.

43. Gundersen C, Kreider B, Pepper J. The economics of food insecurity in the United States. Appl Econ Perspect Policy. 2011;33(3): 281-303. https://doi.org/10.1093/aepp/ppr022.

44. Bartfeld J, Dunifon R. State-level predictors of food insecurity among households with children. J Policy Anal Manag. 2006;25(4):921-42 JSTOR.

45. Dorn AV, Cooney RE, Sabin ML. COVID-19 exacerbating inequalities in the US. Lancet. 2020;395(10232):1243-4. https:// doi.org/10.1016/S0140-6736(20)30893-X.

46. Power M, Doherty B, Pybus K, Pickett K. How COVID-19 has exposed inequalities in the UK food system?: The case of UK food and poverty. Emerald Open Res. 2020;2:11. https://doi.org/10. 35241/emeraldopenres.13539.2.

47. Government of Canada. The Daily-Labour Force Survey, June 2020. July 10, 2020 https://www150.statcan.gc.ca/n1/dailyquotidien/200710/dq200710a-cansim-eng.htm.

48. International Monetery Fund. Policy Responses to COVID19. IMF. 2020. https://www.imf.org/en/Topics/imf-and-covid19/PolicyResponses-to-COVID-19. Accessed 18 Aug 2020.

49. Kaplan J 14 countries that are paying their workers during quarantine - and how they compare to America's \$1,200 stimulus checks. MSN. April 15, 2020. https://www.msn.com/en-sg/news/ photos/14-countries-that-are-paying-their-workers-duringquarantine-\%E2\%80\%94-and-how-they-compare-to-americasdollar1200-stimulus-checks/ss-BB12I9Mr. Accessed 18 Aug 2020
50. Britneff B Food banks' demand surges amid COVID-19. Now they worry about long-term pressures. Global News. April 15, 2020. https://globalnews.ca/news/6816023/food-bank-demand-covid-19long-term-worry/. Accessed 18 Aug 2020.

51. Toronto Public Health. COVID-19 infection in Toronto: Ethnoracial identity and income. 2020. https://public.tableau.com/ profile/tphseu\#!/vizhome/RaceIncomeandCOVID-19Infection/ Proportions. Accessed 01 Sept 2020.

52. Wolf MS, Serper M, Opsasnick L, O'Conor RM, Curtis L, Benavente JY, et al. Awareness, attitudes, and actions related to COVID-19 among adults with chronic conditions at the onset of the U.S. outbreak: a cross-sectional survey. Ann Intern Med. 2020;173(2):100-9. https://doi.org/10.7326/M20-1239.

53. Statistics Canada. Diversity of the Black population in Canada: an overview. 2020. https://www150.statcan.gc.ca/n1/pub/89-657-x/ 89-657-x2019002-eng.htm. Accessed 19 Aug 2020.

54. Balkissoon D Canada's dire need for better race-based data. Macleans. June 08, 2020. https://www.macleans.ca/opinion/ canadas-dire-need-better-race-based-data/

55. Williams SE Danger for nation's African American communities. 2020. https://blackvoicenews.com/2020/03/23/warning-warningcovid-19-presents-enhanced-danger-for-nations-african-americancommunities/. Accessed 19 Aug 2020.

56. Schlosberg J, Davis L, Ghebremedhin S. Philadelphia doctor takes to streets to help Black communities get tested for COVID-19. 2020. https://abcnews.go.com/US/philadelphia-doctor-takesstreets-black-communities-tested-covid/story?id=70405257. Accessed 13 Aug 2020.

57. Government of Canada. Social determinants of health and health inequalities. https://www.canada.ca/en/public-health/services/ health-promotion/population-health/what-determines-health.html. 2019. Accessed 10 Aug 2020.

58. Shavers VL, Shavers BS. Racism and health inequity among Americans. J Natl Med Assoc. 2006;98(3):386-96.

59. Bailey Z, Linos N, Bassett MT. Inequities in the mortality rates of older Americans-race, sex, place, and time. JAMA Netw Open. 2020;3(8):e2012437. https://doi.org/10.1001/jamanetworkopen. 2020.12437 .

60. Blow CM. The racial time bomb in the Covid-19 crisis. The New York Times. April 01, 2020. https://www.nytimes.com/2020/04/01/ opinion/coronavirus-black-people.html. Accessed 06 Aug 2020.

61. Ansah IGK, Gardebroek C, Ihle R. Resilience and household food security: a review of concepts, methodological approaches and empirical evidence. Food Sec. 2019;11:1187-203. https://doi.org/10. 1007/s12571-019-00968-1.

62. Jones MM. The American Red Cross and local response to the 1918 influenza pandemic: a four-city case study. Public Health Rep. 2010;125(Supp1 3):92-104. https://doi.org/10.1177/ $00333549101250 \mathrm{~S} 312$.

63. Huff AG, Beyeler WE, Kelley NS, McNitt JA. How resilient is the United States' food system to pandemics? J Environ Stud Sci. 2015;5(3):337-47. https://doi.org/10.1007/s13412-015-0275-3.

Publisher's Note Springer Nature remains neutral with regard to jurisdictional claims in published maps and institutional affiliations. 